\title{
Systematic bias of average winter-time land surface temperatures inferred from MODIS at a site on Svalbard, Norway
}

\author{
Sebastian Westermann ${ }^{\mathrm{a}, \mathrm{b}, *}$, Moritz Langer ${ }^{\mathrm{a}}$, Julia Boike ${ }^{\mathrm{a}}$ \\ a Alfred-Wegener-Institute for Polar and Marine Research, Telegrafenberg A6, 14473 Potsdam, Germany \\ b Department of Geosciences, University of Oslo, P.O. Box 1047, Blindern, 0316 Oslo, Norway
}

\section{A R T I C L E I N F O}

Article history:

Received 7 June 2011

Received in revised form 24 October 2011

Accepted 29 October 2011

Available online 17 December 2011

\section{Keywords:}

Land surface temperature

MODIS

Snow

Winter

Permafrost

Svalbard

\begin{abstract}
A B S T R A C T
Thermal remote sensing can quantify climate change in the Arctic, where ground-based measurements continue to be rare. The land surface temperature (LST) is accessible on the pan-arctic scale through a number of remote sensing platforms, such as the "Moderate Resolution Imaging Spectrometer" (MODIS). This study compares remotely sensed LST from MODIS to ground-based point measurements of the snow surface temperature on Svalbard for seven consecutive winters, thus covering more than half of the winter seasons in the operation period of MODIS Terra and Aqua. We find a systematic negative bias of the average winter surface temperature computed from single LST measurements between 1.5 and $6 \mathrm{~K}$, with a mean bias of $3 \mathrm{~K}$. The bias consistently occurs both for the MODIS L2 and for the daily and eight-day MODIS L3 products, which is explained by two reasons: i) During winter on Svalbard, cold surface temperatures are associated with clear-sky conditions, while warm surface temperatures typically occur during overcast periods. This leads to an overrepresentation of cold temperature in averages computed from remotely sensed LST measurements. ii) The MODIS cloud detection scheme fails to recognize some cloud-covered or partially cloudcovered situations, thus leading to admixing of colder cloud top temperatures. Both effects contribute equally to the total average bias accumulated over the winter season, with effect (i) dominating in some winters, while the observed bias can be fully explained by (ii) in other winters.
\end{abstract}

(c) 2011 Elsevier Inc. All rights reserved.

\section{Introduction}

The land surface temperature (LST) has been accessible on the global scale through a number of remote sensing platforms for almost three decades. While early LST sensors, such as the "Advanced Very High Resolution Radiometer" (AVHRR) could only offer a limited accuracy of LST, the "Moderate Resolution Imaging Spectroradiometer" (MODIS) launched on board the Terra and Aqua satellites in 1999 and 2002 has provided a global record of LST with a target accuracy of $1 \mathrm{~K}$. The satellite-based thermal sensors are powerful tools for environmental monitoring, e.g. for detection of fires (Justice et al., 2002) or volcanic activity (Wright et al., 2002), but they also provide direct evidence of climate change. This is of particular importance in the vast areas of the Arctic, where land-based observations are extremely sparse (e.g. Stroeve \& Steffen, 1998). In a comprehensive study, Comiso (2003) disclosed a warming of clear-sky LST of 0.5 to $1 \mathrm{~K}$ per decade for many regions in the Arctic using the 1981 to 2002 record of AVHRR.

Thermal remote sensing can only measure LST under clear-sky conditions. In the Arctic winter, the presence of clouds has a distinct

\footnotetext{
* Corresponding author at: Department of Geosciences, University of Oslo, P.O. Box 1047, Blindern, 0316 Oslo, Norway. Tel. +47 22855927.

E-mail address: sebastian.westermann@geo.uio.no (S. Westermann).
}

impact on the surface temperature (Miller, 1956), with reported average differences between cloud-free and cloud-covered skies of 8 to $10 \mathrm{~K}$ (Walsh \& Chapman, 1998). Thus, changes in cloudiness have the potential to mask trends in true LST (Wang \& Key, 2003). By comparing remotely sensed surface temperatures over arctic sea ice with near-surface air temperatures from the "European Centre for Medium-Range Weather Forecasts re-analysis" (ERA, Uppala et al., 2006), Liu et al. (2008) demonstrate that clouds have an effect on the magnitude of the trend, but not on the sign.

The strong differences in LST between cloud-free and cloudcovered conditions may still pose a problem for applications, where the absolute value of the average temperature is important. For modeling of permafrost extent (Hachem et al., 2008) or temperatures (Marchenko et al., 2009) using remotely sensed LST, accurate longterm averages of LST are crucial, as the thawing of permafrost is a threshold process associated with the melting point of ice. Therefore, the success of such modeling schemes critically depends on the capacity of the satellite-based LST sensor to reproduce average LST over periods of days to months. Validation of the thermal sensors (e.g. Wan et al., 2002; Wang et al., 2008) traditionally focuses on single satellite measurements, i.e. satellite measurements are compared to land-based in-situ measurements conducted at the same time within the footprint of the satellite sensor. For ice and snow surfaces in Greenland (Hall et al., 2008) and for sea ice in the Arctic (Hall et al., 
2004) and off Antarctica (Scambos et al., 2006), a generally good agreement between single MODIS LST and in-situ measurements is found. However, there are only few studies on the accuracy of LST averages for longer time periods. For the summer season when the ground is snow-free, Langer et al. (2010) and Westermann et al. (2011b) focus on weekly averages and demonstrate an agreement generally better than $2 \mathrm{~K}$ between remotely sensed LST from MODIS and ground-based measurements for permafrost sites in Siberia and Svalbard, respectively. On the Greenland ice sheet, Koenig and Hall (2010) find a considerable cold-bias of the wintertime average surface temperatures computed from MODIS LST for one winter season, which they attribute to the overrepresentation of cold clear-sky conditions in the satellite time series.

In this study, we compare average snow surface temperatures from a ground-based sensor to averages inferred from MODIS LST products for seven winter seasons for a permafrost site on Svalbard. We analyze the governing factors leading to a bias of the remotely sensed average LST in detail and provide a further assessment for the prospects of MODIS LST in permafrost monitoring schemes.

\section{Methods}

\subsection{Study area}

In the area around Ny-Ålesund, "lowland" permafrost with relatively gentle topography is restricted to an about 2 to $4 \mathrm{~km}$ wide strip along the coast of the Kongsfjorden, which is bordered by the inland glaciers and mountain chains of the Brøgger peninsula to the other side. The field measurements have been conducted in a tundra area in the catchment of the Bayelva river, located southwest of the village of Ny-Ålesund (Fig. 1). The study area is situated about halfway between the glacier Brøggerbreen, from which the Bayelva river originates, and the Kongsfjorden. It is characterized by hilly tundra at elevations between $10 \mathrm{~m}$ and $50 \mathrm{~m}$ above sea level. Sparse vegetation alternates with exposed soil and rockfields, and periglacial landforms, such as mud boils (Boike et al., 2008) and sorted circles, are found in many parts of the study area. The area in the foreland of the glacier Brøggerbreen and around the Bayelva River consists of moraines and wide gravel plains, which during summer display a distinctly different surface cover compared to the tundra areas. During winter, the snow cover is almost continuous, with only negligible fractions of the snow-free surfaces due to wind redistribution of the snow (Westermann et al., 2009). Situated at $78^{\circ} 55^{\prime} \mathrm{N}, 11^{\circ} 50^{\prime} \mathrm{E}$ on top of Leirhaugen hill approximately $2 \mathrm{~km}$ from Ny-Ålesund, the Bayelva climate and soil monitoring station has provided a longterm record of climatological parameters and soil temperatures (Boike et al., 2010; Roth \& Boike, 2001; Westermann et al., 2009).

\subsection{Theory and instrumentation}

The outgoing long-wave radiation $L_{\text {out }}$ and the surface temperature $T_{\text {surf }}$ are related by Stefan-Boltzmann Law and Kirchhoff's Law as

$L_{\text {out }}=\varepsilon \sigma_{\mathrm{S}} T_{\text {surf }}^{4}+(1-\varepsilon) L_{\text {in }}$,

where $L_{\text {in }}$ denotes the incoming long-wave radiation, $\varepsilon$ the emissivity of the surface and $\sigma_{\mathrm{S}}$ the Stefan-Boltzmann constant. We use an emissivity value of 0.985 , which is in the range of typical literature values of snow (Dozier \& Warren, 1982; Hori et al., 2006). From measurements of $L_{\text {out }}$ and $L_{\mathrm{in}}$, the surface temperature can hence be inferred from Eq. (1).

At the Bayelva station, $L_{\text {out }}$ has been measured at 1-min-intervals with a Kipp \& Zonen CG1 long-wave radiation sensor since 2002. Hourly averages are stored on a Campbell Scientific datalogger. The accuracy of the employed sensor has been estimated to be about $3 \mathrm{Wm}^{-2}$ under field conditions (Obleitner \& De Wolde, 1999), but it is very likely that single measurements with stronger deviations due to sensor icing are contained in the data set. The incoming long-wave radiation is measured in the village of Ny-Ålesund at a station of the Baseline Surface Radiation Network (BSRN), where radiation is measured according to WMO accuracy standards (Ohmura et al., 1998). The use of $L_{\text {in }}$ measured approximately $2 \mathrm{~km}$ from the Bayelva station is justified as $L_{\text {in }}$ is controlled by the cloudiness and the vertical profiles of air temperature and water vapor, which do not change strongly over such distances (Curry et al., 1996). Considering the accuracy of the long-wave radiation sensors and an uncertainty of about 0.01 on the emissivity of the snow (which approximately reflects the spread of the literature values), we estimate an accuracy of about $1.5 \mathrm{~K}$ for single surface temperature measurements. This accuracy is confirmed by surface temperature measurements during the snow melt period, when the snow has a known temperature of $0{ }^{\circ} \mathrm{C}$.

From the available time series of hourly data, we calculate the average surface temperature for the winter seasons from 2002/2003 to

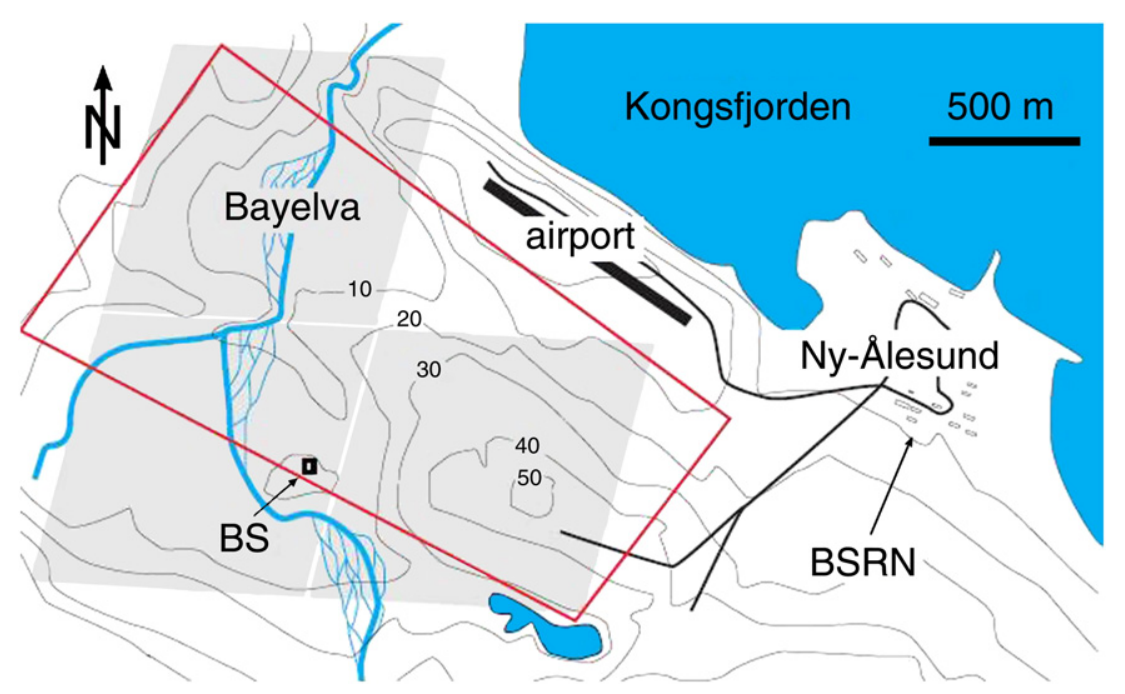

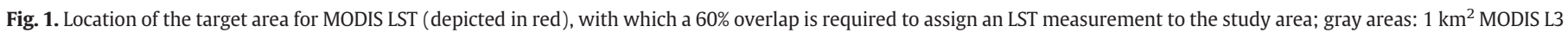
pixels (see text); BS: location of the Bayelva station; BSRN: location of the BSRN station; thick black lines: roads; contour lines in meters above sea level. 
2008/2009, which we define as the period from November 1 to April 15. During this period, the ground has been covered by snow for all years and strong melting of snow, which could introduce a considerable spatial variability of the surface temperature, has not occurred, except maybe during sporadic wintertime rain events (Putkonen \& Roe, 2003; Westermann et al., 2011a).

Supporting data used in this study include: snow depth measured at the Bayelva station (Campbell Scientific SR50), cloudiness in parts of eight according to visual inspection and air temperature in the village of Ny-Ålesund (www.eklima.no, 2010).

\subsection{MODIS LST data}

The version 5 MODIS L2 LST products (MOD11_ L2.5 and MYD11_ L2.5) contain radiometrically corrected surface temperatures obtained by the generalized split window approach (Wan \& Dozier, 1996), where each value corresponds to a direct measurement of a certain footprint area. To compare in-situ and satellite-based measurements, we evaluate the footprint of the satellite measurements, as described in detail in Langer et al. (2010) and Westermann et al. (2011b). The unprojected swath data format of the L2 product (Wan, 2008) and the geolocation fields L1A V005 (Wolfe et al., 2002) provide the exact acquisition time and geometrical acquisition parameters, from which the footprint area of the measurement can be computed. We define a target area of approximately $2 \mathrm{~km} \times 1 \mathrm{~km}$ (Fig. 1) and calculate the overlap between the footprint and the target area for each satellite measurement. The target area, which is selected from field observations, mainly consists of hilly tundra similar to the vicinity of the Bayelva station, and features an almost continuous snow cover in winter. To achieve a sufficient data density, the study is based on satellite measurements, where the footprint ellipse and the target area overlap by at least $60 \%$, but the results are crosschecked using only measurements with $90 \%$ overlap. In both cases, major contributions of the Kongsfjorden and the glacier Brøggerbreen to the footprint area do not occur. For each season, on the order of 2500 MODIS granules are available, which provide LST measurements fulfilling the overlap criterion with the target area depicted in Fig. 1. However, only about $25 \%$ to $30 \%$ represent clear-sky conditions at the target area and thus contain valid LST measurements. From the available satellite measurements, we calculate LST averages from 1 November to 15 April for the winter seasons from 2002/2003 to $2008 / 2009$.

In addition, we compute the winter-time average LST from the gridded daily (MOD11A1/MYD11A1) and eight-day (MOD11A2/ MYD11A2) L3 products of MODIS Terra and Aqua. They feature a spatial resolution of $1 \mathrm{~km}$ and provide a value for the day and night LST for both the Terra and Aqua satellites, which are all employed with equal weight to compute the average. The position of the grid cells with respect to the Bayelva station is shown in Fig. 1. To compare with the in-situ measurements, the lower right pixel is employed, as this is mainly characterized by vegetated tundra surface similar to the direct area surrounding the Bayelva station. We emphasize that an explicit control of the footprint area of the satellite measurements is not possible with the L3 products.

\section{Results}

\subsection{Comparison of in-situ and satellite measurements of wintertime LST}

\subsubsection{Clear-sky LST}

Fig. 2 displays a comparison of clear-sky surface temperatures obtained from MODIS L2 LST and in-situ measurements at the Bayelva station, of which the hourly value closest in to the acquisition time of the MODIS LST measurement is employed. Despite a considerable spread, the agreement between terrestrial and satellite measurements is excellent for surface temperatures colder than $-15^{\circ} \mathrm{C}$, but the performance rapidly degrades towards $0{ }^{\circ} \mathrm{C}$, where MODIS LST features a cold-bias of on average more than $10 \mathrm{~K}$.

\subsubsection{LST averages}

The average wintertime ( 1 Nov to 15 Apr) LST computed from MODIS LST products features a systematic cold-bias in all of the investigated years (Table 1 ). The average surface temperature derived from the MODIS L2 product is systematically biased to colder temperatures by on average $3.0 \mathrm{~K}$. With about $3.5 \mathrm{~K}$, the bias is even stronger for the LST averages computed from the both the daily and the eightday MODIS L3 products.

\subsection{Impact of clouds on the surface temperature and MODIS LST acquisition}

At the village of Ny-Ålesund, routine observations of the cloud fraction are conducted (www.eklima.no, 2010), so that the impact of cloudiness on the surface temperature and satellite-based LST measurements can be directly investigated. Fig. 3a and b display the average daily surface and near-surface air temperatures vs. the average daily cloud fraction for the winter periods as defined in Section 2. There is a clear correlation between cloud fraction and both surface and air temperature, with the surface temperature being on average more than $15 \mathrm{~K}$ colder for clear compared to fully cloud-covered skies. The difference is less pronounced for the near-surface air temperature, which can be explained by strong near-surface inversions forming particularly during times of low incoming long-wave radiation in case of cloud-free skies (Westermann et al., 2009). For cloud-covered skies, the average surface and air temperatures are almost equal as near-surface inversions are much less pronounced in this case. Fig. 4 is clear evidence for the effect of clouds on the acquisition of MODIS LST. As to be expected, clouds strongly reduce the number of measurements, but on average there are still two measurements per day for fully cloud-covered skies (Fig. 4b). While this could potentially be attributed to errors in the observations of the cloud

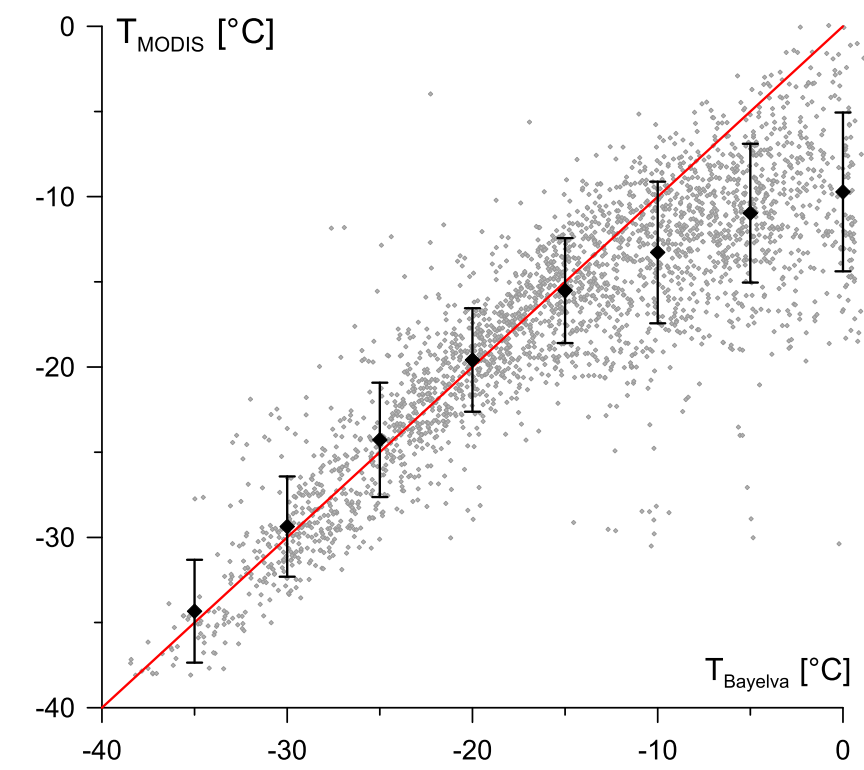

Fig. 2. Comparison of clear-sky MODIS L2 LST (MOD11_ L2/MYD11_ L2) and surface temperature at the Bayelva station (hourly value closest in to the acquisition time of MODIS LST) for the winter periods ( 1 Nov to 15 Apr) 2002/2003 to 2008/2009. Red line: 1:1 line; black rhombs: mean value of bins of $5 \mathrm{~K}$ width (drawn in the center of a bin); error bars: standard deviation $(1 \sigma)$ of the values in a bin. 
Table 1

Average surface temperatures for seven winter seasons (1 Nov to $15 \mathrm{Apr}$ ) from the insitu record of the Bayelva station and the MODIS L2 (MOD11_L2/MYD11_ L2) and daily (MOD11A1/MYD11A1) and eight-day (MOD11A2/MYD11A2) L3 LST products; bias: difference between average of in-situ measurements and average of MODIS L2 LST; Bayelva clear-sky: average of in-situ measurements for times when satellite measurements (as determined from the MODIS L2 product) are available(see text); * data gaps of in total 2 months in the Bayelva series, MODIS LST of these periods not considered in the averages.

\begin{tabular}{|c|c|c|c|c|c|c|}
\hline & \multirow[t]{2}{*}{ Bayelva } & \multirow{2}{*}{$\begin{array}{l}\text { MODIS } \\
\text { L2 }\end{array}$} & \multirow[t]{2}{*}{ Bias } & \multicolumn{2}{|c|}{ MODIS L3 } & \multirow{2}{*}{$\frac{\text { Bayelva }}{\text { Clear-sky }}$} \\
\hline & & & & Daily & 8-day & \\
\hline $2002 / 2003$ & -15.0 & -16.6 & -1.6 & -18.1 & -18.2 & -14.2 \\
\hline $2003 / 2004$ & -16.1 & -22.2 & -6.1 & -20.5 & -20.5 & -20.1 \\
\hline $2004 / 2005$ & -13.8 & -17.0 & -3.2 & -17.2 & -16.9 & -15.4 \\
\hline $2005 / 2006$ & -10.3 & -14.0 & -3.7 & -14.6 & -14.6 & -10.7 \\
\hline $2006 / 2007$ & -12.6 & -14.7 & -2.1 & -15.4 & -15.5 & -13.1 \\
\hline $2007 / 2008^{*}$ & -13.9 & -15.3 & -1.4 & -17.3 & -17.3 & -15.4 \\
\hline $2008 / 2009$ & -13.9 & -17.0 & -3.1 & -17.5 & -18.2 & -15.0 \\
\hline average & -13.7 & -16.7 & -3.0 & -17.2 & -17.3 & -14.8 \\
\hline
\end{tabular}

fraction, Fig. 4a suggests that the reason is rather erroneous cloud detection in the MODIS LST algorithm: the satellite-based measurements are on average about $8 \mathrm{~K}$ too cold for fully cloud-covered skies, which is most likely caused by admixing of colder cloud top temperatures. In contrast, the satellite measurements agree on average well (within $1.5 \mathrm{~K}$ ) with the terrestrial measurements for average daily cloud fractions of less than $50 \%$.

Thus, clouds have a two-fold influence on wintertime averages of surface temperature calculated from MODIS LST: firstly, cold conditions,

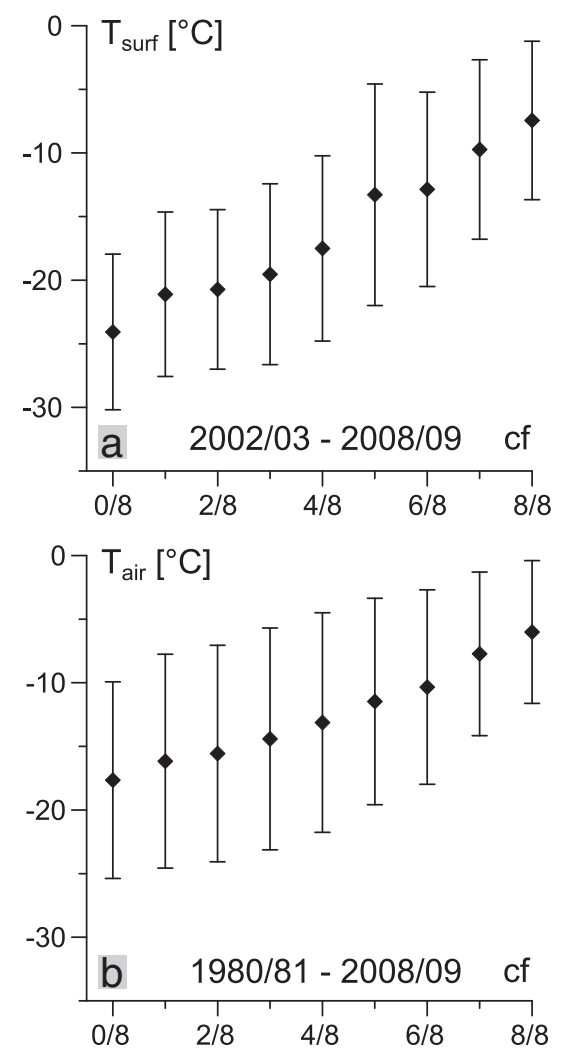

Fig. 3. a) Daily average cloud fraction cf vs. surface temperature (hourly values) at the Bayelva station for seven winter periods. Note that daily average cloud fraction is used, not cloud fraction at the measurement time. b) Daily average cloud fraction cf vs. daily average air temperature at $2 \mathrm{~m}$ height in Ny-Ålesund for 29 winter periods. Error bars: standard deviation $(1 \sigma)$ of values at a cloud fraction.
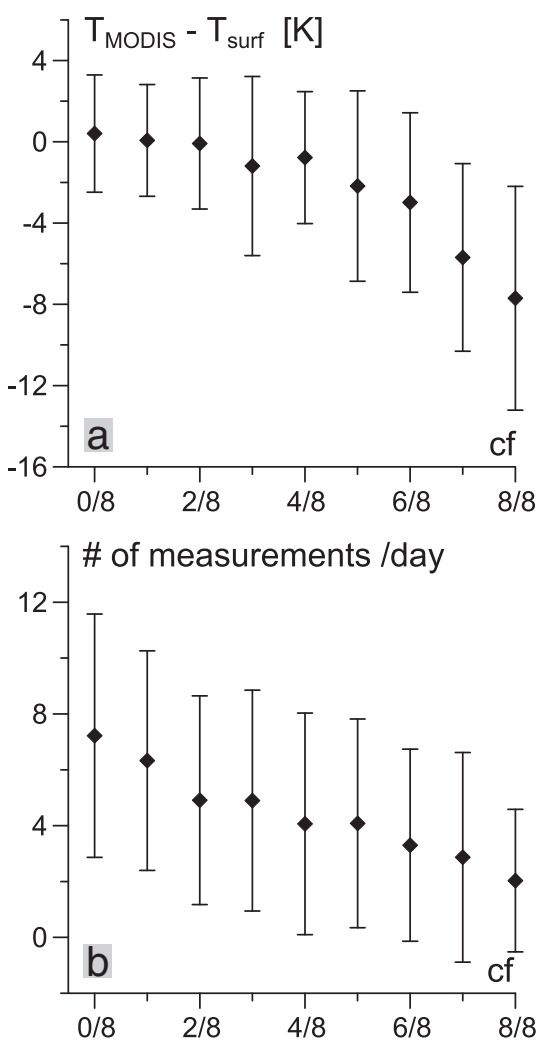

Fig. 4. a) Daily average cloud fraction cf vs. difference between MODIS L2 LST (MOD11_ L2/MYD11_L2) and surface temperature at the Bayelva station (hourly value closest to the time of satellite measurement). Note that daily average cloud fraction is used, not cloud fraction at the measurement time. b) Daily average cloud fraction cf vs. daily number of MODIS L2 LST measurements (fulfilling the overlap criterion with the target area). Data from winter periods (1 Nov to 15 Apr) 2002/03 to 2008/09; error bars: standard deviation $(1 \sigma)$ of values at a cloud fraction.

which predominantly occur during clear-sky conditions in the study area, are systematically overrepresented in temporal averages, since satellite measurements are sparse during prolonged cloudy periods. Secondly, valid MODIS LST measurements exist even for fully cloudcovered skies due to erroneous cloud detection, which on average are strongly cold-biased compared to the in-situ measurements. To separate the two error sources, we delimit the surface temperature record of the Bayelva station to times, when a MODIS LST measurement is available, and calculate a seasonal "in-situ clear-sky average" from these measurements (Table 1, last column). If the MODIS LST average (Table 1, 3rd column) is equal to this in-situ clear-sky average, single MODIS LST measurements are (at least on average) accurate and the bias is caused by the overrepresentation of clear-sky conditions. On the other hand, if the in-situ clear-sky average is equal to the "true" average of all in-situ measurements (Table 1,2nd column), the cold-bias is due to erroneous MODIS LST measurements of cloud-covered or partly cloud-covered scenes. Table 1 demonstrates that both error sources contribute equally to the formation of the cold-bias. However, single years exist where one of the two sources dominates, which we illustrate for two example years (Fig. 5). The winter 2003/2004 is the coldest in the record, and the satellite-based LST average is close to the average clear-sky surface temperature at the Bayelva station, so that the strong deviation between satellite and in-situ average can be largely explained by overrepresentation of cold clear-sky conditions in the average. Indeed, the MODIS LST measurements are strongly concentrated in periods with cold surface temperatures, while measurements are almost completely missing during the regular events when the surface temperature is close to $0{ }^{\circ} \mathrm{C}$. The agreement between single MODIS LST 
measurements and the in-situ record is generally good (within $1.5 \mathrm{~K}$ ). In the second example year 2005/2006, which features the warmest average surface temperatures in the record, the average clear-sky surface temperature is almost equal to the true average surface temperature, so that systematic overrepresentation of cold periods can only play a minor role in explaining the cold-bias of about $3.5 \mathrm{~K}$ of MODIS LST. Instead, a large number of strongly cold-biased MODIS LST measurements are observed during prolonged periods of warm surface temperatures in the range from $-5{ }^{\circ} \mathrm{C}$ and $0{ }^{\circ} \mathrm{C}$. The cold-bias of single measurements regularly exceeds $10 \mathrm{~K}$, which classifies them as measurement errors most likely caused by admixing of cloud top temperatures. The same is actually observed in the much colder winter $2003 / 2004$, e.g. at the beginning of November, beginning of January and beginning of March. However, as the warm periods are much shorter than in $2005 / 2006$, these erroneous measurements play only a minor role.

\section{Discussion}

\subsection{MODIS LST}

There is clearly a scaling gap between the in-situ point measurements and the MODIS footprint. However, the uniform snow cover within the target area makes spatial differences of the magnitude that would be necessary to explain the detected cold-bias unlikely (see also Koenig \& Hall, 2010). This is supported by an evaluation of
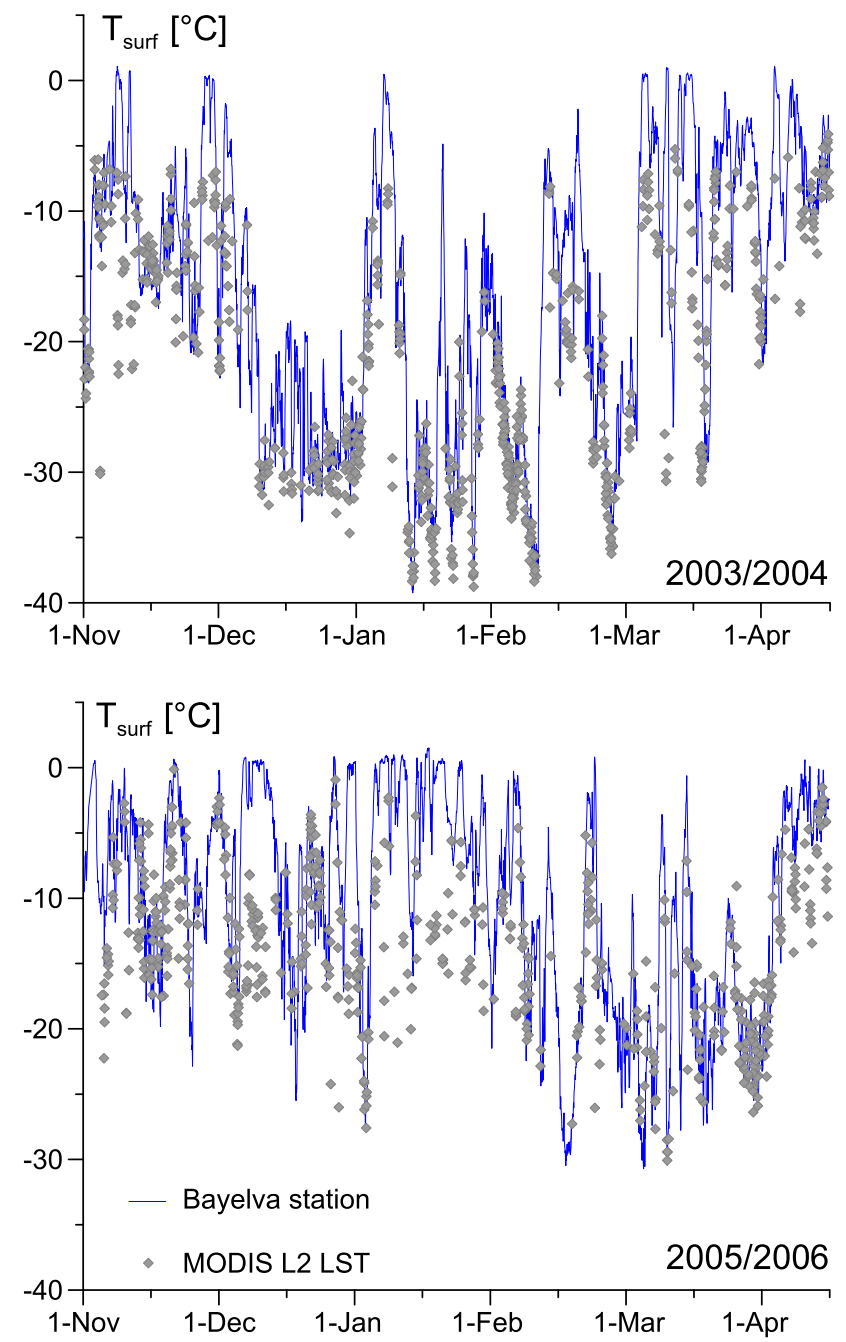

Fig. 5. Comparison of MODIS L2 LST (MOD11_L2/MYD11_L2) and surface temperature measured at the Bayelva climate station for the periods between 1 Nov and 15 Apr for the winter seasons 2003/2004 and 2005/2006. two other MODIS L3 LST pixels contained in the target area (Fig. 1), which both feature wintertime averages within $0.5 \mathrm{~K}$ of the pixel shown in Table 1. Nevertheless, it is possible that the scatter between single in-situ and MODIS LST measurements (Fig. 2) is at least partly caused by areas in the satellite footprint featuring slightly different surface temperatures compared to the Bayelva station.

A number of studies have pointed out shortcomings of the MODIS cloud detection algorithm under night conditions and for low sun angles (Liu et al., 2010), which occur continuously during the arctic winter. However, strongly erroneous MODIS LST measurements have also been reported for the summer season (Langer et al., 2010; Westermann et al., 2011b), which also cause a strong bias in weekly LST averages, if they are not discarded. Therefore, caution seems warranted when using remotely sensed LST to derive long-term temporal averages of the surface temperature.

While the average winter surface temperature at the Bayelva station has increased since 2002, the time series of in-situ measurements of seven winter seasons is still too short to reveal statistically significant trends due to a large interannual variability. However, the warming is observed both for cloud-free and for cloud-covered conditions, which is in qualitative agreement with the findings of Liu et al. (2008), who show that trends obtained from remotely sensed LST agree well in sign and to a lesser extent in magnitude with trends in modeled nearsurface air temperatures from ERA reanalysis.

\subsection{Implications for permafrost monitoring}

For permafrost monitoring schemes using remotely sensed land surface temperatures, accurate temporal LST averages are required. A wintertime cold-bias of on average about $3 \mathrm{~K}$ as determined in this study could thus constitute an important error source, at least in regions with winter conditions similar to Svalbard. The cold-bias is partly inherent in the measurement principle of thermal remote sensing, since satellite LST measurements are impossible in case of cloudy conditions. Thus, a robust gap-filling procedure for cloudcovered periods is necessary to employ MODIS LST for permafrost monitoring. Hachem et al. (2009) use a simple scheme based on the sinusoidal course of the annual temperature. A more sophisticated scheme could make use of the results of an atmospheric circulation model, e.g. reanalysis products (e.g. Uppala et al., 2006). In case of cloudy skies, near-surface air temperatures provided by such a model could be employed, since the air temperature is then similar to the surface temperature (compare Fig. 3). Furthermore, it may be possible to detect and discard strongly biased LST measurements by comparing with atmospheric model data, so that the impact of erroneous cloud detection could be moderated.

\section{Summary and conclusions}

In this study, we compare wintertime averages of the snow surface temperature computed from different MODIS LST products to averages of in-situ measurements. The investigations have been conducted at a high-arctic permafrost site on Svalbard and comprise seven winter seasons, thus spanning more than half of the operation period of MODIS Terra and Aqua. We find a significant cold-bias of on average $3 \mathrm{~K}$ for the MODIS LST wintertime averages, with values ranging from 1.5 and $6 \mathrm{~K}$ for single seasons. The bias is partly caused by the lack of satellite measurements during prolonged periods with cloud-covered skies, where the surface temperature is on average considerably higher than during cloud-free periods. Furthermore, strongly cold-biased biased LST measurements are contained in the MODIS data set, which contribute to the observed cold-bias of the seasonal averages. As they almost exclusively occur during cloudy periods, the cold-bias can be attributed to admixing of colder cloud top temperatures due to erroneous cloud detection. 
The study shows that caution is warranted when using remotely sensed land surface temperatures to obtain long-term averages under arctic winter conditions. More work towards understanding the error sources inherent in thermal remote sensing products is desirable to make use of the full potential of thermal remote sensing for monitoring the climate of high-latitude areas.

\section{Acknowledgments}

We are grateful to M. Maturilli for providing us with the data of the BSRN station. We thank the staff of the AWIPEV base in Ny-Ålesund for the ongoing support of our permafrost research, which contributed greatly to the success of this work. The MODIS LST data were obtained through the online Data Pool at the NASA Land Processes Distributed Active Archive Center (LP DAAC), USGS/Earth Resources Observation and Science (EROS) Center, Sioux Falls, South Dakota (http://lpdaac. usgs.gov/get_data). We gratefully acknowledge financial support by the Helmholtz Association through a grant (VH-NG 203) awarded to Julia Boike.

\section{References}

Boike, J., Ippisch, O., Overduin, P., Hagedorn, B., \& Roth, K. (2008). Water, heat and solute dynamics of a mud boil, Spitsbergen. Geomorphology, 95(1-2), 61-73.

Boike, J., Westermann, S., Piel, K., \& Overduin, P. (2010). Warming of permafrost temperatures on Svalbard - What is the effect of the snow cover? European Conference on Permafrost, Longyearbyen, Norway.

Comiso, J. (2003). Warming trends in the Arctic from clear sky satellite observations. Journal of Climate, 16(21), 3498-3510.

Curry, J., Rossow, W., Randall, D., \& Schramm, J. (1996). Overview of Arctic cloud and radiation characteristics. Journal of Climate, 9(8), 1731-1764.

Dozier, J., \& Warren, S. (1982). Effect of viewing angle on the infrared brightness temperature of snow. Water Resources Research, 18(5), 1424-1434.

Hachem, S., Allard, M., \& Duguay, C. (2008). A new permafrost map of Quebec-Labrador derived from near-surface temperature data of the moderate resolution imaging spectroradiometer (MODIS). Proceedings, NICOP, Vol. I. (pp. 591-596).

Hachem, S., Allard, M., \& Duguay, C. (2009). Using the MODIS land surface temperature product for mapping permafrost: An application to northern Québec and Labrador, Canada. Permafrost and Periglacial Processes, 20(4), 407-416.

Hall, D., Box, J., Casey, K., Hook, S., Shuman, C., \& Steffen, K. (2008). Comparison of satellite-derived and in-situ observations of ice and snow surface temperatures over Greenland. Remote Sensing of Environment, 112(10), 3739-3749.

Hall, D., Key, J., Casey, K., Riggs, G., \& Cavalieri, D. (2004). Sea ice surface temperature product from MODIS. IEEE transactions on geoscience and remote sensing, 42(5), 1076-1087.

Hori, M., Aoki, T., Tanikawa, T., Motoyoshi, H., Hachikubo, A., Sugiura, K., et al. (2006). In-situ measured spectral directional emissivity of snow and ice in the 8-14 $\mu \mathrm{m}$ atmospheric window. Remote Sensing of Environment, 100(4), 486-502.

Justice, C., Giglio, L., Korontzi, S., Owens, J., Morisette, J., Roy, D., et al. (2002). The MODIS fire products. Remote Sensing of Environment, 83(1-2), 244-262.

Koenig, L., \& Hall, D. (2010). Comparison of satellite, thermochron and air temperatures at Summit, Greenland, during the winter of 2008/09. Journal of Glaciology, 56(198), 735-741.

Langer, M., Westermann, S., \& Boike, J. (2010). Spatial and temporal variations of summer surface temperatures of wet polygonal tundra in Siberia-Implications for MODIS LST based permafrost monitoring. Remote Sensing of Environment, 114(9), 2059-2069.
Liu, Y., Ackerman, S., Maddux, B., Key, J., \& Frey, R. (2010). Errors in cloud detection over the Arctic using a satellite imager and implications for observing feedback mechanisms. Journal of Climate, 23(7), 1894-1907.

Liu, Y., Key, J., \& Wang, X. (2008). The influence of changes in cloud cover on recent surface temperature trends in the Arctic. Journal of Climate, 21(4), 705-715.

Marchenko, S., Hachem, S., Romanovsky, V., \& Duguay, C. (2009). Permafrost and active layer modeling in the Northern Eurasia using MODIS Land Surface Temperature as an input data. Geophysical Research Abstracts, 11 EGU2009-11077.

Miller, D. (1956). The influence of snow cover on local climate in greenland. Journal of Atmospheric Sciences, 13, 112-120.

Obleitner, F., \& De Wolde, J. (1999). On intercomparison of instruments used within the Vatnajökull glacio-meteorological experiment. Boundary-Layer Meteorology, 92(1), $25-35$.

Ohmura, A., Gilgen, H., Hegner, H., Müller, G., Wild, M., Dutton, E., et al. (1998). Baseline Surface Radiation Network (BSRN/WCRP): New precision radiometry for climate research. Bulletin of the American Meteorological Society, 79(10), 2115-2136.

Putkonen, J., \& Roe, G. (2003). Rain-on-snow events impact soil temperatures and affect ungulate survival. Geophysical Research Letters, 30(4), 1188.

Roth, K., \& Boike, J. (2001). Quantifying the thermal dynamics of a permafrost site near Ny-Ålesund, Svalbard. Water Resources Research, 37(12), 2901-2914.

Scambos, T., Haran, T., \& Massom, R. (2006). Validation of AVHRR and MODIS ice surface temperature products using in situ radiometers. Annals of Glaciology, 44(1), 345-351.

Stroeve, J., \& Steffen, K. (1998). Variability of avhrr-derived clear-sky surface temperature over the Greenland ice sheet. Journal of Applied Meteorology, 37(1), 23-31.

Uppala, S., Kållberg, P., Simmons, A., Andrae, U., Bechtold, V., Fiorino, M., et al. (2006). The ERA-40 re-analysis. Quarterly Journal of the Royal Meteorological Society, 131(612), 2961-3012.

Walsh, J., \& Chapman, W. (1998). Arctic cloud-radiation-temperature associations in observational data and atmospheric reanalyses. Journal of Climate, 11(11), 3030-3045.

Wan, Z. (2008). New refinements and validation of the MODIS land-surface temperature/emissivity products. Remote Sensing of Environment, 112(1), 59-74.

Wan, Z., \& Dozier, J. (1996). A generalized split-window algorithm for retrieving landsurface temperature from space. IEEE transactions on geoscience and remote sensing, 34(4), 892-905.

Wan, Z., Zhang, Y., Zhang, Q., \& Li, Z. (2002). Validation of the land-surface temperature products retrieved from Terra Moderate Resolution Imaging Spectroradiometer data. Remote Sensing of Environment, 83(1-2), 163-180.

Wang, X., \& Key, J. (2003). Recent trends in arctic surface, cloud, and radiation properties from space. Science, 299(5613), 1725-1728.

Wang, W., Liang, S., \& Meyers, T. (2008). Validating MODIS land surface temperature products using long-term nighttime ground measurements. Remote Sensing of Environment, 112(3), 623-635.

Westermann, S., Boike, J., Langer, M., Schuler, T. V., \& Etzelmüller, B. (2011). Modeling the impact of wintertime rain events on the thermal regime of permafrost. The Cryosphere, 5, 945-959. doi:10.5194/tc-5-945-2011.

Westermann, S., Langer, M., \& Boike, J. (2011). Spatial and temporal variations of summer surface temperatures of high-arctic tundra on Svalbard-Implications for MODIS LST based permafrost monitoring. Remote Sensing of Environment, 115(3), 908-922.

Westermann, S., Lüers, J., Langer, M., Piel, K., \& Boike, J. (2009). The annual surface energy budget of a high-arctic permafrost site on Svalbard, Norway. The Cryosphere, 3(2), 245-263 URL. http://www.the-cryosphere.net/3/245/2009/

Wolfe, R., Nishihama, M., Fleig, A., Kuyper, J., Roy, D., Storey, J., et al. (2002). Achieving sub-pixel geolocation accuracy in support of MODIS land science. Remote Sensing of Environment, 83(1), 31-49.

Wright, R., Flynn, L., Garbeil, H., Harris, A., \& Pilger, E. (2002). Automated volcanic eruption detection using MODIS. Remote Sensing of Environment, 82(1), 135-155.

www.eklima.no (2010). Free access to weather- and climate data from Norwegian Meteorological Institute from historical data to real time observations. URL. http:// www.eklima.no 